\title{
Self-stigma as a mediator between social capital and empowerment among people with major depressive disorder in Europe: the ASPEN study
}

Lanfredi M. a, Zoppei S. ??, Ferrari C. ? Bonetto C. ??, Van Bortel T. ??, Thornicroft G. ${ }^{\text {e, }}$ Knifton L. ${ }^{\text { }}$, Quinn N. ${ }^{\text {, }}$, Rossi G. ${ }^{\text {a }}$, Lasalvia A. ? and the ASPEN Study group *

a Unit of Psychiatry, IRCCS Istituto Centro San Giovanni di Dio Fatebenefratelli, Brescia, Italy

b Department of Public Health and Community Medicine, Section of Psychiatry, University of Verona, Verona, Italy

c IRCCS Istituto Centro San Giovanni di Dio Fatebenefratelli, Brescia, Italy

d Cambridge Institute of Public Health, University of Cambridge, Cambridge, UK

e Health Service and Population Research Department, Institute of Psychiatry, King's College London, London, UK

f School of Applied Social Sciences, University of Strathclyde, Glasgow, UK

\section{Corresponding author}

Dr. Mariangela Lanfredi

Unit of Psychiatry, IRCCS Istituto Centro San Giovanni di Dio Fatebenefratelli, via Pilastroni 4, I-25125,

Brescia, Italy; tel.: +390303501504, fax: +390303501592, e-mail: mlanfredi@fatebenefratelli.it

Word count: manuscript including abstract and references (5092) 


\begin{abstract}
Introduction: Individual social capital has been recognized to have an important role for health and well-being. We aimed to test the hypothesis that poor social capital increases internalized stigma and, in turn, can reduce empowerment among people with major depressive disorder (MDD).

Materials and Methods: This is a cross-sectional multisite study conducted on a sample of 516 people with MDD recruited in 19 European countries. Structural Equation Models were developed to examine the direct and indirect effects of self-stigma and social capital on empowerment.

Results: Social capital and self-stigma accounted for $56 \%$ of the variability of empowerment. Higher social capital was related with lower self-stigma $(r=-0.72$, $\mathrm{p}<0.001$ ), which, in turn, partially mediated the relationship between social capital and empowerment $(\mathrm{r}=0.38, \mathrm{p}<0.001)$.

Conclusions: Social capital plays a key role in empowerment appraisal, also via the indirect effect mediated by self-stigma. In order to improve empowerment of people with MDD we pointed out the need for identifying strategies to foster individual social capital and to overcome negative consequences related to self-stigma on life goals attainment.
\end{abstract}

Key words: self-stigma; depression; empowerment; social capital 


\section{Introduction}

Stigma and discrimination have a serious negative impact on the lives of people with depression. A recent multisite international study among people with Major Depressive Disorder (MDD), reported that up to $37 \%$ of respondents stopped themselves from doing something important in their life (e.g. close interpersonal relationships, applying for work or education) due to the expectation to be discriminated against [21]. Considering that the WHO ranked depression as the second leading cause of worldwide disability by the year 2020 [32] and that, beside symptomatology, people with depression have to cope with many of the same negative attitudes, inadequate healthcare and social barriers reported by people with other severe mental disorders [26], it is essential to explore factors related to higher level of stigmatization experienced by people with MDD.

One key issue to be considered in the stigmatization process is the role of self-stigma, i.e. the result of internalization of shame, blame, hopelessness, guilt and fear of discrimination associated with having a mental disorder [12]. Previous literature suggests that higher levels of self-stigma are associated with lower levels of hope, empowerment, self-esteem, self-efficacy, quality of life and social support in people with mental health problems [24]. However, most of early research on internalized stigma mainly focuses on people with schizophrenia or other forms of psychosis [24], whereas little attention has been paid to people with MDD. Self-stigma and perceived stigma by individuals with mental health problems appear to adversely affect adherence to treatment and to limit intentions to seek professional help for depressive symptoms [2, 16]. Mental health related stigma has negative social consequences for people with mental health problems, including exclusion within families and communities and discrimination in employment, education and housing [48].

The relationship between stigmatization and social contexts within which the process takes place is bidirectional in two ways. First, stigma can undermine social networks and perceived social support of people with mental health problems. In this regard, the "modified labelling theory" [23] suggests that perceived stigma and the related expectation to be devaluated and discriminated against, leads to avoidance of social contact by people with mental health problems. Second, lower levels of social support or social networks were found to be associated with higher perceived stigmatization among 
patients with severe mental health problems [7, 30-31, 39, 44]. The GAMIAN Europe study pointed out that $27 \%$ of the variance in self-stigma scores was predicted by levels of empowerment, perceived discrimination and numbers of areas of social contacts among people with bipolar and unipolar depression [7].

Social contacts and social networks are closely related to the overall concept of "social capital" [3]. Social capital is increasingly being recognized as important for health and well-being [18]. It is a multi-dimensional construct encompassing diverse aspects such as trust [9], social norms and reciprocity [34], features of social structures and resources embedded within one's social networks [22]. At the ecological level, low level of social capital was found to be associated to suicide in European countries [19] and people with depression with more access to social capital were found to achieve better outcomes after a 6-months period [46]. At the individual level, cognitive components of social capital have been found inversely related to psychological distress [40] and to be associated to higher risk of depression [20]. Furthermore, lower access to social capital resources was found associated to higher anticipated discrimination in people with severe mental illness [47] and higher levels of experienced discrimination in people with major depression [51].

In our study, we gathered under the umbrella term "individual social capital" both structural (social networks) and cognitive (perceived social support and interpersonal trust) aspects of social capital.

Moreover, self-stigma and, to a lesser extent, increased rejection experiences, harm levels of empowerment [25], which has been defined as a process of gaining control over decisions about main domains of life [10]. Lower levels of empowerment or proxy measures (e.g. self-concepts such as mastery, self-efficacy and self-esteem), have been shown to be related to depression and to a reduction in quality of life [39].

In recent decades, Structural Equation Models (SEM) and Path Models have been used to explore the relationship between psycho-social variables and different aspects of stigma in people with schizophrenia or severe mental health problems [14, 31, 39, 44].

However, so far and to the best of our knowledge, no studies using SEM explored the complex interrelations between self-stigma, individual social capital and empowerment among people with depressive disorders. 
In this study we aimed to validate, in a large sample of people with MDD from across Europe, the hypothesis that poor individual social capital increases internalized stigma which, in turn, can hinder empowerment. In particular, we examined the hypothesis that poor individual social capital and higher self-stigma directly influence the level of empowerment. In addition, we tested simultaneously the hypothesis that social capital indirectly affects empowerment mediated through the intensity of reported self-stigma.

\section{Materials and methods}

\subsection{Study design}

This is a cross-sectional study conducted within the framework of the ASPEN study, a multi-site project aiming to explore stigma and discrimination and related factors among people with depression across Europe [21]. An overall sample of 527 patients with a diagnosis of MDD were recruited across 19 sites located in 18 European countries (Belgium, Bulgaria, England, Finland, France, Germany, Greece, Hungary, Italy [Brescia and Verona], Lithuania, the Netherlands, Portugal, Romania, Scotland, Slovakia, Slovenia, Spain, and Turkey). Participants were interviewed face-to-face by trained researchers not involved in the care process with an extensive set of study instruments, including measures for empowerment and self-stigma (see paragraph 2.2). From the 19 ASPEN sites, 16 sites located in 15 countries also collected data on social capital $(n=433)$ (Romania, Scotland and Spain did not participate in this assessment).

Full details on sample recruitment are given elsewhere [21]. In brief, between January and December 2010, a minimum of 25 participants in each participating site was consecutively recruited from local public or private specialist mental health services (outpatients and day care clinics) and assessed with the study instruments. This sampling method, also adopted in previous international multisite studies [41], was deliberately intended to allow local staff to take into account the specific local service configuration and to draw participants from the whole range of appropriate local services where people with MDD receive treatment from specialist mental health services. No compensation was provided for study participation. Inclusion criteria were: a diagnosis of Major Depressive Disorder (MDD) (single episode or recurrent) according to DSM-IV-TR criteria; a major depressive episode within the past 12 months (but not at time of 
interview); signed informed consent; ability to understand and speak the main local language; at least 18 years old. Exclusion criterion was: being a psychiatric in-patient at the time of recruitment. The study was approved by the local research Ethics Committee at each study site.

\subsection{Measures}

2.2.1 Social capital. We included three different indicators for evaluating individual social capital. Perceived social support was assessed with the Oslo 3-Item Social Support Scale [27], which contains three items concerning: number of people the participant reports being close to; concern shown by others; and ease of getting practical help from neighbours. It provides an overall social support index score where higher scores indicate higher levels of social support. Using current data, Cronbach's alpha reliability was consistent with other studies and equal to 0.6 [13,43]. With regard to social network, three items from the European Social Survey (ESS) [15] were included, exploring relationships, contacts in social life and level of participation in the community. The sum score of the ordinal items gave the collective social network (ranging from 3 to 14, higher scores indicating higher social network) and a Cronbach's alpha of 0.64. Finally, for interpersonal trust, responses on three questions from the ESS [15] on a 10-point Likert scale ranging from 0 ('no trust') to 10 ('highest trust') were collected; the score was calculated by combining the three items. Also for this measure, we found a Cronbach's alpha of 0.82 , which substantially overlaps with those reported in previous studies using the ESS [45, 33].

2.2.2 Self-stigma. The subjective experience of stigma was assessed with the Internalized Stigma of Mental Illness (ISMI) scale [35], which consists of 29 items each rated on a 4point Likert scale (ranging from 1= "strongly disagree" to $4=$ "strongly agree") with higher scores indicating higher internalized stigma. The ISMI includes five subscales: alienation, stereotype endorsement, discrimination experience, social withdrawal and stigma resistance. Since stigma resistance was found to be a separate construct [37], the stigma resistance subscale items have not been included in the total ISMI score. Selfstigma is referred to the combined average of the other four ISMI subscales. Consistency measured by Cronbach's alpha was 0.89 . 
2.2.3 Empowerment. Subjective feelings of empowerment were assessed using the Boston University Empowerment Scale (BUES) [36]. This scale contains 28 items measured on a 4-point Likert scale (1= "I strongly disagree" to $4=$ "I strongly agree"). The BUES scale consists of five subscales: power, righteous anger, self-esteem/self-efficacy, community activism and autonomy, optimism and control over future. Higher score on each BUES subscales reflects high empowerment. Consistency (Cronbach's alpha) was 0.84 .

\subsection{Statistical analysis}

Summary statistics were carried out through means and standard deviations (SDs) for continuous variables, and frequencies and percentages for discrete variables.

Preliminary association analysis between individual socio-demographic (gender, age, family status, living situation, education, employment status) and clinical variables (number of depressive episode, previous admission for psychiatric care, age at the first treatment for a mental health problem) with total ISMI and total BUES scores were examined by t-tests and two linear regression models (ISMI and BUES scores as dependent variables). Two analyses of covariance (ANCOVA) adjusted for "country" factor were applied to evaluate putative significant relationship between self-stigma (as dependent variable) and empowerment, social support, interpersonal trust, social network (as independent variables), and between empowerment (as dependent variable) and social capital indicators (as independent variables). We then examined the interrelations between observed and latent variables by SEM [6]. The main advantage of using SEM is the flexibility to model complex relationships between one or more independent (exogenous) variables and one or more dependent (endogenous) variables simultaneously. Moreover, the contribution of each subscales to corresponding latent construct could be easily carried out. The goodness of fit of the model, to test if the hypothesized model is a plausible explanatory model for the empirical data, was checked

by several measures: $\chi^{2}$ test, relative $\chi^{2}$ test and comparative fit index (CFI), root mean square error of approximation (RMSEA), Tucker-Lewis coefficient (TLI) and Akaike information criterion (AIC).

The hypothesized model (see Figure 1), included three latent variables: self-stigma that was indexed with four subscale items of the ISMI scale; empowerment was measured 
using four subscales items of the BUES scale; social capital as the common factor of the three instruments social support, social networks and interpersonal trust.

The model designated both social capital and self-stigma as predictors of empowerment, and self-stigma as mediator of empowerment. Moreover, number of lifetime depressive episodes ( $\leq 5$ vs. $\geq 6$ depressive episodes), previous psychiatric admissions (yes vs. no), employment status (paid work vs. unpaid work), were included in SEM model as exogenous variables based on their significant associations with ISMI and/or BUES as detected in previous analyses. Five hundred and sixteen patients who filled out both the ISMI and the BUES scales were included in the model. For those patients not assessed with social capital measures (having been recruited in the three sites which did not consent to collect this additional information), missing data (83 for both social trust and support, 84 for social network) were handled by Bayesian multiple imputation [38]. This method ensures the stability of estimates that in our study were obtained by averaging across ten different imputed data sets [1]. Moreover, the Bayesian method allowed us to directly model the missing data process (through prior parameter specification) providing robust estimates also in case of violation of missing at random assumption. Multivariate normal distribution assumption was tested and confirmed: skewness and kurtosis or each parameter was between \pm 2 . All statistical analysis were carried out by using SPSS 21.0, SEM was implemented by package AMOS 21.0. Statistical significance was set at $\mathrm{p}<0.05$.

\section{Results}

\subsection{Patients' characteristics}

From the overall sample recruited in the ASPEN study $(n=527), 516$ completed both the

ISMI and BUES scales. Their socio-demographic and clinical characteristics are given in Table 1.

$<$ Insert Table 1 about here $>$

The mean age of respondents was 46.6 years $(\mathrm{SD}=15.3)$, more than half were female $(68.2 \%)$, moreover $47.7 \%$ was married or co-habiting and $39.2 \%$ hade a paid work. The 
majority of respondents $(96.8 \%)$ agreed with the diagnosis for which they were being treated. The mean age of first treatment for mental illness was 35.8 years $(\mathrm{SD}=15.0)$.

Table 2 provides the distributions of ISMI, BUES and social capital mean scores.

$<$ Insert Table 2 about here>

The overall mean ISMI score was 2.2 (range 1-4), thus indicating a low-moderate level of internalized stigma [7]. Similarly, the overall BUES mean score was 2.7 (range 1-4), indicating moderate levels of endorsement of empowerment [7]. With regard to social support and social network, the mean scores were 8.9 and 8.3 in a range of 3-14, indicating that participants reported moderate-high levels of social support [27] and social network. Finally, the mean score of interpersonal trust (range 0-10) was equal to 4.6 $( \pm 2.1)$ that revealed a quite fair-moderate trust toward other people.

\subsection{Relationships between ISMI, BUES and Social Capital}

Associations between socio-demographic and clinical variables with ISMI and BUES respectively were tested to select variables to include in SEM (see Table 3).

\section{$<$ Insert Table 3 and Table 4 about here $>$}

Gender, age, family status, living situation, education, and age at first contact with mental health services were not significantly related to ISMI and BUES scores, hence none of them were included in the model. Previous psychiatric admissions were associated to higher ISMI scores $(\mathrm{p}=0.004)$. Unemployed people and participants with more than 6 lifetime depressive episodes were associated with higher ISMI scores $(\mathrm{p}<0.001$ and $\mathrm{p}=0.004$ respectively) and lower BUES scores ( $\mathrm{p}=0.020$ and $\mathrm{p}<0.001$ respectively).

Similarly, ANCOVA models, adjusted for site factor, were used to select outcome variables to be included in the SEM model (see Table 4). Significant inverse correlations were found between social capital indicators and ISMI score. Higher scores on social support, social network, interpersonal trust were found associated to higher BUES scores. Moreover, lower BUES scores were significantly correlated to higher ISMI scores. Finally, comparison of ANCOVA models with and without adjustment for site factor 
were carried out: predictor estimates of two models did not differ, thus it was decided to not consider the "site" variable in SEM.

\subsection{Structural equation model}

The hypothesized structural equation model (see Figure 1) involved all variables significantly associated to ISMI and BUES and the plausible relations between the latent constructs (circle in figure) and observed variables (rectangle in figure) are reported.

\section{$<$ Insert Figure 1 about here $>$}

There was no evidence of association between admission for psychiatric care and selfstigma. Moreover, number of depressive episodes and employment were not found significantly associated neither with self-stigma or empowerment. The final model is reported in Figure 2.

\section{$<$ Insert Figure 2 about here >}

The number of distinct parameters to be estimated was 45, including covariance parameters between exogenous variables for improving the model fit. Model fit indices showed a good fit for the data $\left(\chi^{2}=35.916, \mathrm{df}=32, \mathrm{p}=0.290\right.$; relative $\chi^{2}=1.122, \mathrm{CFI}=$ 0.998; TLI = 0.997, RSMEA=0.015 (90\%CI 0.000-0.037) and AIC= 125.891).

Latent constructs were well defined by their indicators. By comparing the factor loading of social capital, we noted that the main contributors to the latent construct were given by social support and social network (with factor loading equal to 0.69 and 0.64 ); whereas the main contributors to the empowerment and self-stigma latent construct were given by self-esteem and optimism (with factor loading equal to 0.86 and 0.83 ) and social withdrawal and alienation (with factor loading equal to 0.87 and 0.84 ) respectively. Differently, righteous anger subscale had a low factor loading (0.08) and it was removed from indicators of latent variable empowerment. Social capital and self-stigma accounted for $56 \%$ of the total variability of empowerment. Social capital had a direct and negative effect on self-stigma $(r=-0.72, p<0.001$ and $52 \%$ of self-stigma variability explained by 
social capital) indicating that higher social capital was related with lower self-stigma. Moreover, social capital had both a direct effect $(r=0.27 \mathrm{p}<0.001)$ and an indirect effect $(\mathrm{r}=0.38, \mathrm{p}<0.001)$ on empowerment, suggesting that self-stigma partially mediated [4] the relationship between social capital and empowerment.

\section{Discussion}

The aim of this study was to test inter-relationships between social capital, self-stigma and empowerment among people with MDD. SEM analysis confirmed that poor social capital contributes to increased self-stigma and indirectly hinder clients' empowerment. This result is in line with previous studies that pointed to a relationship between an aspect of social capital, namely social network, and self-stigma in people suffering from other psychiatric conditions [30, 39]. Similarly, a previous study [49] found that perceived discrimination, acts as a mediator between negative social interactions and another variable related to empowerment, such as quality of life of people with mental health problems. Moreover, we confirmed that higher self-stigma contributed to a lack of empowerment [39, 44].

Results of our study support the hypothesis that social capital is a predictor of empowerment among people with MDD, both directly and indirectly via the mediated effect of self-stigma. A possible explanation is that a supportive environment might reduce the negative effects of depression-related stigma and consequently build individual self-esteem and optimism.

The progressive model of self-stigma proposed by Corrigan [12] argued that stereotype awareness and stereotype agreement lead individuals to apply these views to one-self and to reduce self-efficacy and self-esteem. Self-stigma has been regarded as obverse of personal empowerment [37]. The fact that some individuals develop low self-esteem while others remain indifferent to stigma or react with empowerment and righteous indignation about discrimination - i.e., the "paradox of self-stigma and mental illness" [11] - seems to depend on in-group perception and the perceived legitimacy of the discrimination [37].

The theory of the buffering effect [8] suggests that social support might operate as a moderator in reducing the negative effects of stressors on psychological well-being. 
Differently, our model shows that self-stigma is a mediator of the impact of individual social capital on empowerment. In the analyses of stress processes, stress related to prejudice and discrimination has been figured as an additional source of stress that acts as a mediator between a series of disadvantaged social statuses and mental health problems [28] and there is also evidence that stigma leads to depression [39]. In this regard, a previous study [17] proposed a model in which social relationships are considered to contribute to improved well-being when providing help to face negative life stressors (e.g. emotional support, instrumental support, informational support), but only when these acts are perceived as satisfying basic psychological needs (e.g. sense of belonging, feeling to be able to cope with difficulties).

We hypothesize that perceptions of the availability of emotional support or advices on how to face problems may increase positive in-group perception of people with MDD and, in turn, decrease the likelihood of stereotype agreement. On the basis of our results, it is suggested that higher social capital might foster the level of individual sense of empowerment directly and also by reducing the appraisal of stigma as a source of stress. Social support from family, friends and social network and interpersonal trust may be considered social and psychological resources to cope with threats to individual identity as discrimination [5]. In this sense, family psycho-education, peer support and coaching should be stimulated in order to prompt the activation of supportive networks and to improve effective empowering coping strategies to enhance individual skills for coping with self-stigma [29]. Moreover, some evidence suggests that psychological interventions such as cognitive-behavioural techniques, narrative enhancement or group-based acceptance and commitment therapy may have the potential to reduce self-stigma [29]. SEM analyses did not provide any significant association between number of depressive episodes and previous psychiatric admissions with self-stigma. This is in line with previous studies which found that self-stigma did not predict clinical outcomes or medication adherence in depressed patients at 1-year follow up [50]. In addition, although ANCOVA found an association between employment status and level of self-stigma, this relationship was not supported by SEM. Further research is required to explore whether depressed people with lower income would have reduced access to social capital compared to people with a higher income. It is possible that a lower access to social resources such as social support might decrease resilience to stigma and discrimination. 
Consistent with previous studies [14, 31], we found that self-stigma was not significantly associated with any other socio-demographic variables.

This study has a number of limitations. Its cross-sectional design prevented us from establishing relations of causality and this study did not address other possible factors that could explain more variance in the empowerment construct. Unfortunately, we did not have data on psychopathology or personality structures in our sample because these assessments were beyond the scope of the study. Hence, data need to be interpreted with caution, since reports of low social capital may reflect a consequence of depression's severity and negative cognitive style [42] rather than representing an independent variable. In line with previous research, we found that most participants reported low levels of self-stigma [7, 14] and moderate-high levels of social support and social network [39]. Potential selection bias should be taken into account. For example, 84\% of the sample were post-acute outpatients, for this reason people who never accessed professional care were under-represented. There are numerous factors that may influence the self-stigma process, so further studies should include target populations such as groups who are marginalised due to aspects of social circumstances (e.g., economic disadvantage) or through aspects of identity (e.g., ethnicity).

\section{Conclusions}

We found empirical evidence that self-stigma partially mediates the positive relationship between social capital and individual sense of empowerment. Therefore, in order to increase empowerment of people with depression, strategies to foster individual social capital (comprising of the perceptions of support, reciprocity in social life, sharing and trust among people) should be pursued.

Disclosure of interest: The authors declare they have no conflicts of interest.

\section{Acknowledgments}

\section{The ASPEN Study Group (C) 2012}

Staff at Co-ordinating Centres: Graham Thornicroft, Tine Van Bortel, Samantha Treacy, Elaine Brohan, Shuntaro Ando, Diana Rose (King's College London, Institute of Psychiatry, London, England); Kristian Wahlbeck, Esa Aromaa, Johanna Nordmyr, 
Fredrica Nyqvist, Carolina Herberts (National Institute for Health and Welfare, Vaasa, Finland); Oliver Lewis, Jasna Russo, Dorottya Karsay, Rea Maglajlic (Mental Disability Advocacy Centre, Budapest, Hungary); Antonio Lasalvia, Silvia Zoppei, Doriana Cristofalo, Chiara Bonetto (Department of Public Health and Community Medicine, Section of Psychiatry and Clinical Psychology, University of Verona, Italy); Isabella Goldie, Lee Knifton, Neil Quinn (Mental Health Foundation, Glasgow, Scotland); Norman Sartorius (Association for the improvement of mental health programmes (AMH), Geneva, Switzerland).

Staff at Partner Centres: Chantal Van Audenhove, Gert Scheerder, Else Tambuyzer (Katholieke_Universiteit Leuven (K.U. Leuven), Belgium; Valentina Hristakeva, Dimitar Germanov (Global Initiative on Psychiatry Sofia (GIP-Sofia), Bulgaria); Jean Luc Roelandt, Simon Vasseur_Bacle, Nicolas Daumerie, Aude Caria (Etablissement Public Santé Mentale Lille-Métropole (EPSM/C.C.OMS), France); Harald Zaske, Wolfgang Gaebel (Heinrich-Heine Universitat Dusseldorf, Rheinische Kliniken Dusseldorf (RKD), Germany); Marina Economou, Eleni Louki, Lily Peppou, Klio Geroulanou (University Mental Health Institute (UMHRI (EPIPSI), Greece); Judit Harangozo, Julia Sebes, Gabor Csukly (Awakenings Foundation (AWF), Hungary); Giuseppe Rossi, Mariangela Lanfredi, Laura Pedrini (Unit of Psychiatry, IRCCS Istituto Centro San Giovanni di Dio Fatebenefratelli, Brescia, Italy); Arunas Germanavicius, Natalja Markovskaja, Vytis Valantinas (Vilnius University (VU), Lithuania); Jaap van Weeghel, Jenny Boumans, Eleonoor Willemsen, Annette Plooy (Stichting Kenniscentrum Phrenos (KcP), Netherlands); Teresa Duarte, Fatima Jorge Monteiro (Associaçãopara o Estudo e Integração Psicossocial (AEIPS), Portugal); Janka Hurova, Dita Leczova (Association for Mental Health INTEGRA, o. z. (Integra o.z.), Slovakia); Vesna Svab, Nina Konecnik (University Psychiatric Hospital (PKL), Slovenia); Alp Ucok, Gulsah Karaday (Foundation of Psychiatry Clinic of Medical Faculty of Istanbul (PAP), Turkey).

Funding: European Union in the framework of the Public Health Programme. 


\section{References}

[1] Allison PD, Missing data techniques for structural equation modeling. J Abnorm Psychol 2003;112:545-57.

[2] Barney LJ, Griffiths KM, Jorm AF, Christensen H. Stigma about depression and its impact on help-seeking intentions. Aust N Z J Psychiatry 2006;40:51-4.

[3] Baron S, Field J, Schuller T (eds). Social capital. Critical Perspectives. London: Oxford University Press; 2000.

[4] Baron RM, Kenny DA. The moderator mediator variable distinction in social psychological research: Conceptual, strategic, and statistical considerations. J Pers Soc Psychol 1996;51:1173-182.

[5] Berjot S, Gillet N. Stress and coping with discrimination and stigmatization. Front Psychol 2011;2-33.

[6] Bollen KA. Structural equation with Latent Variables. New York: John Wiley ed.; 1996.

[7] Brohan E, Gauci D, Sartorius N, Thornicroft G, GAMIAN-Europe Study Group. Selfstigma, empowerment and perceived discrimination among people with bipolar disorder or depression in 13 European countries: the GAMIAN-Europe study. J Affect Disord 2011;129:56-63.

[8] Cohen S, Wills TA. Stress, social support, and the buffering hypothesis. Psychol Bull 1985;98:310-57.

[9] Coleman J (1988). Social capital in the creation of human capital. Amer J Sociol 94,S95-S120.

[10] Corrigan PW. Impact of consumer-operated services on empowerment and recovery of people with psychiatric disabilities. Psychiatr Serv 2006;57:1493-96.

[11] Corrigan P, Watson AC The Paradox of Self-Stigma and Mental Illness Clin Psychol Sci Pr 2002;9:35-53.

[12] Corrigan P, Watson AC. The impact of stigma on severe mental illness. Cog Behav Pract 1998;5:201-222.

[13] Dalgard OS, Dowrick C, Lehtinen V, Vazquez-Barquero JL, Casey P, Wilkinson G, et al. Negative life events, social support and gender difference in depression: a multinational community survey with data from the ODIN study. Soc Psychiatry Psychiatr Epidemiol. 2006;41:444-51. 
[14] Drapalski AL, Lucksted A, Perrin PB, Aakre JM, Brown CH, DeForge BR, et al. A model of internalized stigma and its effects on people with mental illness. Psychiatr Serv 2013;64:264-69.

[15] European Social Survey. ESS Round 5 Source Showcards. London: Centre forComparative Social Surveys. London: City University; 2010.

[16] Gaudiano BA, Miller IW. Self-stigma and attitudes about treatment in depressed patients in a hospital setting. Int J Soc Psychiat 2013;59:586-91.

[17] Ibarra-Rovillard MS, Kuiper NA. Social support and social negativity findings in depression: perceived responsiveness to basic psychological needs. Clin Psychol Rev 2011;31:342-52.

[18] Kawachi I, Subramanian SV, Kim D. Social Capital and Health. New York: Springer-Verlag; 2007.

[19] Kelly BD, Davoren M, Mhaolain AN, Breen EG, Casey P. Social capital and suicide in 11 European countries: an ecological analysis. Soc Psychiatry Psychiatr Epidemiol 2009;44:971-977.

[20] Kim SS, Chung Y, Perry MJ, Kawachi I, Subramanian SV. Association between interpersonal trust, reciprocity, and depression in South Korea: a prospective analysis. PLoS One. 2012;7:e30602.

[21] Lasalvia A, Zoppei S, Van Bortel T, Bonetto C, Cristofalo D, Wahlbeck K, et al. Global pattern of experienced and anticipated discrimination reported by people with major depressive disorder: a cross-sectional survey. Lancet 2013;381:55-62.

[22] Lin N. Social Capital. A Theory of Social Structure and Action. Cambridge: Cambridge University Press; 2001.

[23] Link BG, Cullen FT, Struening E, Shrout PE, Dohrenwend BP. A Modified Labeling Theory Approach to Mental Disorders: An Empirical Assessment. Am Sociol Rev 1989;54:100-23.

[24] Livingston JD, Boyd JE. Correlates and consequences of internalized stigma for people living with mental illness: a systematic review and meta-analysis. Soc Sci Med 2010;71:2150-161.

[25] Lundberg B, Hansson L, Wentz E, Björkman T. Are stigma experiences among persons with mental illness, related to perceptions of self-esteem, empowerment and sense of coherence? J Psychiatr Ment Health Nurs. 2009;16:516-22.

[26] McNair BG, Highet NJ, Hickie IB, Davenport TA. Exploring the perspectives of people whose lives have been affected by depression. Med J Aust. 2002;176 Suppl:S6976. 
[27] Meltzer H. Development of a common instrument for mental health. In: Nosikov \& Gudex (eds), Eurohis: Developing Common Instruments for Health Survey. Amsterdam: IOS press; 2003. p. 35-47.

[28] Meyer IH, Schwartz S, Frost DM. Social patterning of stress and coping: does disadvantaged social statuses confer more stress and fewer coping resources? Soc Sci Med. 2008; 67:368-79.

[29] Mittal D, Sullivan G, Chekuri L, Allee E, Corrigan PW. Empirical Studies of SelfStigma Reduction Strategies: A Critical Review of the Literature. Psychiatr Serv 2012;63:974-81.

[30] Mueller B, Nordt C, Lauber C, Rueesch P, Meyer PC, Roessler W. Social support modifies perceived stigmatization in the first years of mental illness: a longitudinal approach. SocSci Med 2006;62:39-49.

[31] Munoz M, Sanz M, Perez-Santos E, Quiroga Mde L. Proposal of a socio-cognitivebehavioral structural equation model of internalized stigma in people with severe and persistent mental illness. Psychiatry Res 2011;186:402-08.

[32] Murray CJL, Lopez AD. The Global Burden of Disease: a comprehensive assessment of mortality and disability from diseases, injuries, and risk factors in 1990 and projected to 2020. Cambridge: Harvard University Press; 1996.

[33] Poortinga W. Social capital: an individual or collective resource for health? Soc Sci Med 2006; 62:292-02.

[34] Putnam R. Bowling Alone. The Collapse and Revival of American Community. New York: Simon \& Schuster; 2000.

[35] Ritsher JB, Otilingam PG, Grajales M. Internalized stigma of mental illness: psychometric properties of a new measure. Psychiatry Res 2003;121:31-49.

[36] Rogers ES, Chamberlin J, Ellison ML, Crean T. A consumer-constructed scale to measure empowerment among users of mental health services. Psychiatr Serv 1997;48:1042-47.

[37] Rusch N, Lieb K, Bohus M, Corrigan PW. Self-stigma, empowerment, and perceived legitimacy of discrimination among women with mental illness. Psychiatr Serv 2006;57:399-02.

[38] Schafer JL. Analysis of incomplete multivariate data. Chapman \& Hall ed. London; 1997.

[39] Sibitz I, Amering M, Unger A, Seyringer ME, Bachmann A, Schrank B, et al. The impact of the social network, stigma and empowerment on the quality of life in patients with schizophrenia. Eur Psychiatry 2011;26:28-33. 
[40] Song L. Social capital and psychological distress. J Health Soc Behav 2011;52:47892.

[41] Thornicroft G, Brohan E, Rose D, Sartorius N, Leese M; INDIGO Study Group. Global pattern of experienced and anticipated discrimination against people with schizophrenia: a cross-sectional survey. Lancet 2009; 373:408-15.

[42] Tse WS, Bond AJ. The impact of depression on social skills. J Nerv Ment Dis 2004; 192:260-8.

[43] Van Lente E, Barry MM, Molcho M, Morgan K, Watson D, Harrington J, et al. Measuring population mental health and social well-being. Int J Public Health. 2012; 57:421-30.

[44] Vauth R, Kleim B, Wirtz M, Corrigan PW. Self-efficacy and empowerment as outcomes of self-stigmatizing and coping in schizophrenia. Psychiatry Res 2007;150:7180 .

[45] Von dem Knesebeck O, Dragano N, Siegrist J. Social capital and self-rated health in 21 European countries. Psychosoc Med 2005; 23;2:Doc02.

[46] Webber M. Huxley P, Harris T. Social capital and the course of depression: sixmonth prospective cohort study. J Affect Disord 2011;129:149-57.

[47] Webber M, Corker E, Hamilton S, Weeks C, Pinfold V, Rose D, et al. Discrimination against people with severe mental illness and their access to social capital: findings from the Viewpoint survey. Epidemiol Psychiatr Sci 2013;20:1-11.

[48] World Health Organization. World health report 2001: New understanding, new hope. Geneva: WHO; 2001.

[49] Yanos PT, Rosenfield S, Horwitz AV. Negative and supportive social interactions and quality of life among persons diagnosed with severe mental illness. Community Ment Health J 2001;37:405-19.

[50] Yen CF, Chen CC, Lee Y, Tang TC, Ko CH, Yen JY. Association between quality of life and self-stigma, insight, and adverse effects of medication in patients with depressive disorders. Depress Anxiety 2009;26:1033-9.

[51] Zoppei S, Lasalvia A, Bonetto C, Van Bortel T, Nyqvist F, et al. Social capital and reported discrimination among people with depression in 15 European countries. Soc Psychiatry Psychiatr Epidemiol 2014 [Epub ahead of print] 
Figure 1. Hypothesized effects of social capital and self-stigma on empowerment, controlled for admission for psychiatric care, number of depressive episodes and employment status.

Figure2. Structural equation model: the rectangles represent the observed variables; the gray elliptic circles symbolize the latent variables. Significance of standardized regression weights is represented with asterisks: ${ }^{*} \mathrm{p}<0.05 ;{ }^{* *} \mathrm{p}<0.001$. White elliptic circles represent variables error. 
Mary J. De Silva, BA, MSc, PhD, Centre for Global Mental Health, London School of Hygiene and Tropical Medicine, Keppel Street, London WC1E 7HT, UK. Email: mary.desilva@Ishtm.ac.uk

Tommy Björkman, Department of Nursing, Lund University, PO Box 157, SE-221 00, Lund, Sweden tommy.bjorkman@omv.lu.se

Roland Vauth, Department of Psychiatric Outpatient Treatment (Psychiatrische Universitätspoliklinik), Psychiatric University Hospital of Basel, Claragraben 95, CH-4057 Basel,

Switzerland.roland.vauth@upkbs.ch 


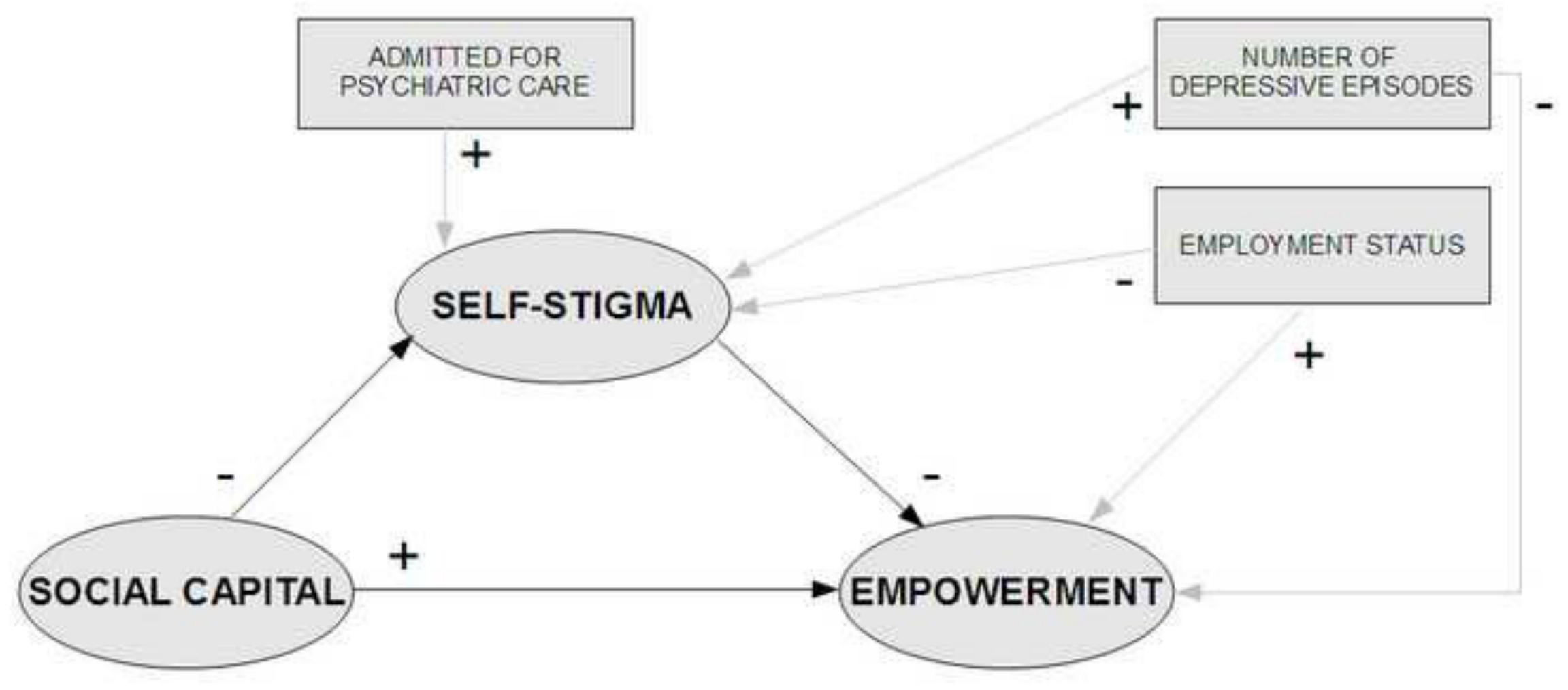




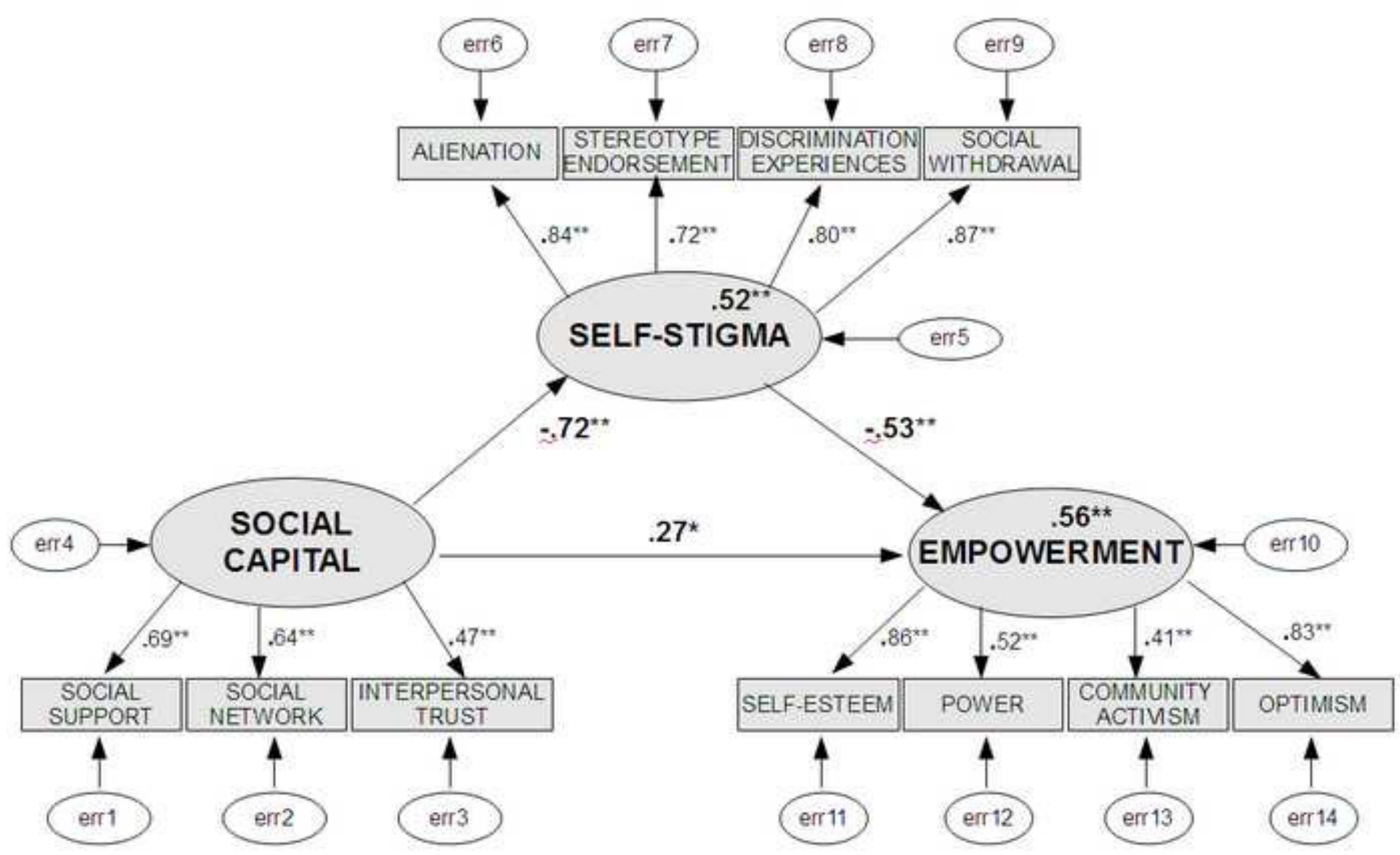


Table 1. Socio-demographic and illness-related characteristics of participants $(n=516)$

\begin{tabular}{llcc}
\hline Variable & Category & $\begin{array}{l}\text { Mean/ } \\
\text { frequency }\end{array}$ & $\begin{array}{l}\text { SD/ } \\
\text { percentage }\end{array}$ \\
\hline Gender & Male & 164 & $31.8 \%$ \\
& Female & 352 & $68.2 \%$ \\
Age (years) & & 46.6 & 15.3 \\
Marital status & Single/non co-habiting partner & 146 & $28.3 \%$ \\
& Separated/Divorced/Widowed & 121 & $23.7 \%$ \\
& Currently married or & 246 & $47.7 \%$ \\
Level of education & cohabiting & & $57.6 \%$ \\
Employment status & At least high school & 296 & $39.2 \%$ \\
Agreement with diagnosis & Paid work & 200 & $96.8 \%$ \\
Ethnic minority & Agree & 475 & $6.8 \%$ \\
Age at the first treatment for a mental & & 29 & 15.0 \\
health problem (years) & Yes & 35.8 & \\
Ever admitted for psychiatric care & Yes & & $42.2 \%$ \\
Lifetime numbers of depressive & $\geq 6$ & 215 & $42.0 \%$ \\
episodes & & 200 & \\
Current type of mental health care & Outpatients & 427 & \\
\hline
\end{tabular}


Table 2. Descriptives of ISMI, BUES, Social support, Social network, Interpersonal trust scores

\begin{tabular}{lccc}
\hline Variable & Range & Mean & SD \\
\hline ISMI* (n=516) & $1-4$ & 2.2 & 0.5 \\
Alienation (A) & & 2.4 & 0.7 \\
Stereotype endorsement (SE) & & 2.0 & 0.5 \\
Discrimination experience (DE) & & 2.1 & 0.6 \\
Social withdrawal (SW) & & 2.3 & 0.7 \\
BUES total (n=516) & & 2.7 & 0.3 \\
Powerless/powerlessness & & 2.4 & 0.4 \\
Righteous Anger & & 2.4 & 0.4 \\
Self-esteem/self-efficacy & & 2.7 & 0.6 \\
Community activism and autonomy & & 3.2 & 0.4 \\
Optimism and control over future & & 2.7 & 0.5 \\
Social support (n=433) & $3-14$ & 8.9 & 2.3 \\
Social network (n=432) & $3-14$ & 8.3 & 2.5 \\
Interpersonal trust (n=433) & $0-10$ & 4.6 & 2.1 \\
\hline
\end{tabular}

* Items from the 'Stigma Resistance' subscale were excluded from analysis; ISMI= Internalized stigma of mental illness scale; BUES= Boston University empowerment scale 
Table 3. Associations of ISMI and BUES (dependent continuous variables) with categorical variables (ttest $)(n=516)$. Only significant associations are shown.

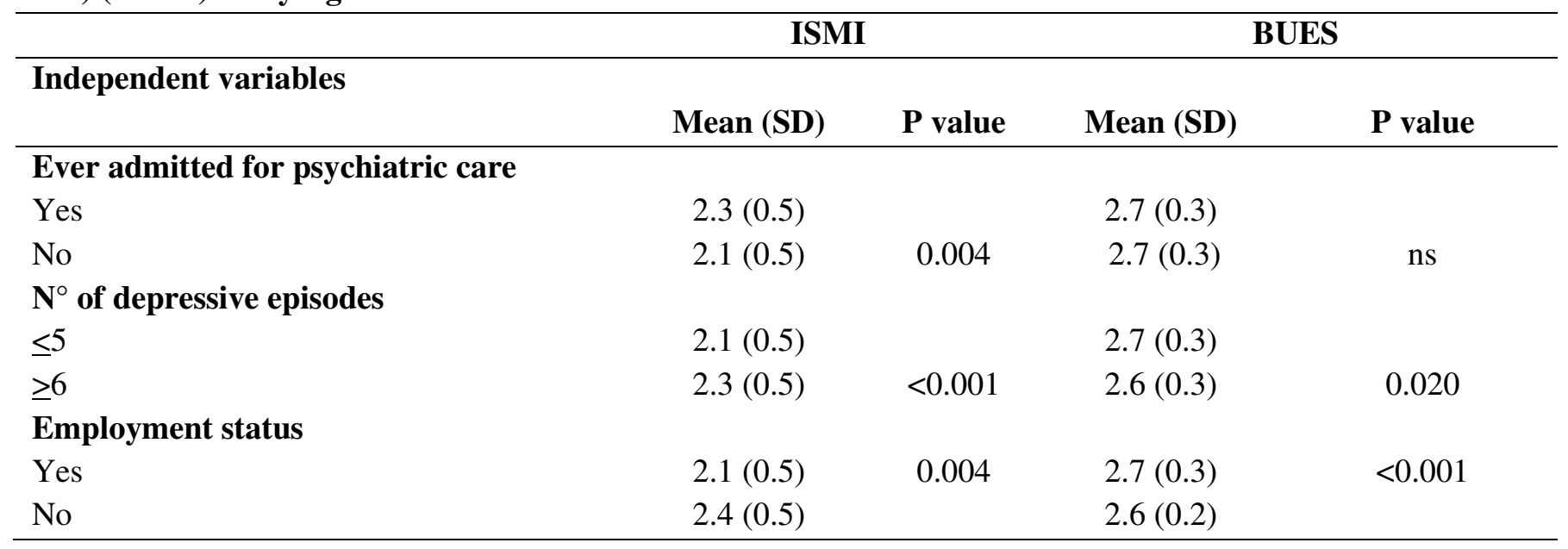

Table 4. Analysis of covariance (ANCOVA), adjusted for site factor, of independent variables associated with dependent variables ISMI and BUES respectively $(n=516)$.

\begin{tabular}{lcccc}
\hline & \multicolumn{2}{c}{ ISMI } & \multicolumn{2}{c}{ BUES } \\
\hline Independent variables & & & & Poeff $(\mathbf{B})$ \\
\hline Social support & P value & Coeff $(\mathbf{B})$ & P value \\
Social network & -0.10 & $<0.001$ & 0.06 & $<0.001$ \\
Interpersonal trust & -0.09 & $<0.001$ & 0.05 & $<0.001$ \\
BUES scale & -0.09 & $<0.001$ & 0.01 & $<0.001$ \\
ISMI scale & -1.04 & $<0.001$ & - & - \\
\hline
\end{tabular}


Self-stigma as a moderator-mediator between social capital and empowerment among consumers-people with major depressive disorder in Europe: the ASPEN study

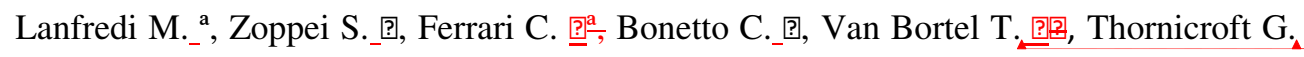

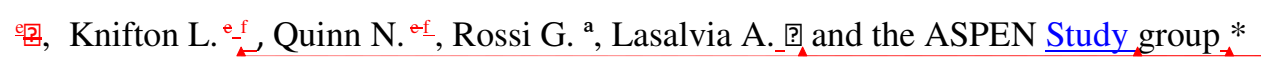

a Unit of Psychiatry, IRCCS Istituto Centro San Giovanni di Dio Fatebenefratelli, di Formatted: Italian (Italy) Formatted: Italian (Italy) Formatted: English (U.S.) Formatted: English (U.S.) Formatted: English (U.S.)

Formatted: English (U.S.) Brescia, Italy

b Department of Public Health and Community Medicine, Section of Psychiatry, University of Verona, Verona, Italy c IRCCS Istituto Centro San Giovanni di Dio Fatebenefratelli, Brescia, Italy, € $\underline{\mathrm{d} \text { Cambridge Institute of Public Health, University of Cambridge, Cambridge, UK }}$ Formatted: Italian (Italy) University of Cambridge, Institute of Public Health A

e Health Services and Population Research Department, Institute of Psychiatry, King's College London, London, UK King's College London, Institute of Psychiatry e

f_School of Applied Social Sciences, University of Strathclyde, Glasgow, UKnited Kingdom

\section{Corresponding author}

Dr. Mariangela Lanfredi 
Unit of Psychiatry, IRCCS Istituto Centro San Giovanni di Dio Fatebenefratelli, via Pilastroni 4, I-25125, Brescia, Italy; tel.: +390303501504, fax: +390303501592, e-mail: mlanfredi@fatebenefratelli.it

Word count: manuscript including abstract and references (5092)

\begin{abstract}
Introduction: Individual social capital has been recognized to have an important role for health and well-being. We aimed to test the hypothesis that poor social capital increases internalized stigma and, in turn, can reduce empowerment among people with major depressive disorders (MDD).

Materials and Methods: This is a_cross-sectional multisite study conducted on a sample of in a multi site sample of 516 people with MDD recruited in 19 European countriesin Europe. Structural Equation Models were developed to examine the direct and indirect effects of self-stigma and social capital-and self stigma-on empowerment.

Results: Social capital and self-stigma accounted for $56 \%$ of the variability of participants' empowerment. Direct and negative effects of social capital on self-stigma $(\mathrm{r}=-0.72, \mathrm{p}<0.001)$ showed that $\mathrm{h}$ Higher social capital was related with lower self-stigma $(\mathrm{r}=-0.72, \mathrm{p}<0.001)$, which, in turn,. Moreover, indirect effects of social capital on empowerment ( $\mathrm{r}=0 \underline{0} .38, \mathrm{p}<0.001)$ suggested that self-stigma-partially mediated the relationship between social capital and empowerment $(\mathrm{r}=0.38, \mathrm{p}<0.001)$.

Conclusions: Social capital plays a key role in empowerment appraisal, also via in buffering the negative effects of self stigma, in particular via the indirect effect_-mediated by self-stigma. In order to improve empowerment of people with MDD we pointed out the need for identifying strategies to foster the improvement of-individual social capital and to overcome negative consequences related to self-stigma on life goals attainment.
\end{abstract}

Key words: self-stigma; depression; empowerment; social capital; 


\section{Introduction}

Recent evidence suggests that $\underline{S}$ stigma and discrimination has have a serious negative impact on the lives of people with Major Depressive Disorders (MDD)depression. A recent multisite international study among people with Major Depressive Disorder (MDD)depression, reported that up to $37 \%$ of respondents stopped themselves from doing something important in their life (e.g. close interpersonal relationships, applying for work or education) due to the expectation to be discriminated against [21]. Considering that the $\mathrm{WHO}$ erld-Health-Organization-ranked depression as the second leading cause of worldwide disability by the year 2020 [32] and that ${ }_{2}$ beside symptomatology, people with depression have to cope with many of the same negative attitudes, inadequate healthcare and social barriers reported by people with other severe mental disorders [26], it is essential to explore factors related to higher level of stigmatization experienced by people with MDDmood disorders.

One key issue to be considered in the stigmatization process is the role of self-stigma, i.e. the result of internalization of shame, blame, hopelessness, guilt and fear of discrimination associated with having a mental disorder [12]. Previous literature suggests that higher levels of self-stigma are associated with lower levels of hope, empowerment, self-esteem, self-efficacy, quality of life and social support in people with mental health problems [24]. However, most of early research on internalized stigma mainly focuses on people with schizophrenia or other forms of psychosis [24], whereas little attention has been paid to people with MDD. Self-stigma and perceived stigma by individuals with mental health problems appears to adversely affect adherence to treatment and to limit intentions to seek professional help for depressive symptoms [2, 16]. Mental health related sStigma against people with mental health problems - has negative social $\underline{\text { consequencescreates a significant social and health impact for people with mental health }}$ problems, including exclusion within families and communities and discrimination in employment, education and housing [48].

The relationship between sStigmatization -and social contexts within which the process takes place is bidirectional in two ways. First, stigma can undermine social networks and perceived social support of people with mental health problems. In this regard, the "modified labelling theory" proposed by Link and colleagues-[23] suggests that perceived 
stigma and the related expectation to be rejected,devaluated and discriminated against, leads to avoidance of social contact by the affected-people with mental health problems. Second, On the other hand, several studies found that-lower levels of social support or social networks were found to be associated with predicted-higher perceived stigmatization among patients with severe mental health problems [7, 30-31, 39, 44]. The GAMIAN Europe study in a reduced multivariate model-pointed out that $27 \%$ of the variance in self-stigma scores was predicted by levels of empowerment, perceived discrimination and numbers of areas of social contacts among people with bipolar and unipolar diagnosis of bipolar disorder or-depression [7].

Social contacts and social networks are closely related to the overall concept of "social capital" [3]. Social capital is increasingly being recognized as important for health and well-being [18]. It is a multi-dimensional construct encompassing diverse aspects such as trust [9], social norms and reciprocity [34], features of social structures and resources embedded within one's social networks [22]. At the ecological level, low level of social capital was found to be associated to suicide in European countries [19] and people with depression with more access to social capital were found to achieve better outcomes after a 6-months period [46]. At the individual level, cognitive components of social capital has-have been found inversely related to psychological distress [40] and to be associated to higher risk of depression [20]. Furthermore, lower access to social capital resources was found associated to higher anticipated discrimination in people with severe mental illness [47] and higher levels of experienced discrimination in people with major depression [51].

In our study, we gathered under the umbrella term "individual social capital" both structural (social networks) and cognitive (perceived social support and interpersonal trust) aspects of social capital. Although epidemiological studies have largely drawn upen Putnam's [39] concept of 'social capital' [16], 'social network approaches' more clearly align the concept with recovery discourses [50].

Moreover, sSelf-stigma and, to a lesser extent, increased rejection experiences, harm levels of empowerment [25] and lack of empowerment is related to depression and leads to a reduction in quality of life $[23,46]$. Moreover, empowerment, which has been defined as a process of gaining control over decisions about main domains of life [10]. Lower levels of empowerment or proxy measures (e.g. self-concepts such as mastery, $4 / 21 \underline{22}$ 
self-efficacy and self-esteem), was -have been shown found to be related to depression and to a reduction in quality of life [39].and to be positively associated with in access to social networks $[21,45]$. social support [11] and number of met needs for care [23]

In recent decades, Structural Equation Models (SEM) and Path Models have been used to explore the relationship between psycho-social variables and different aspects of stigma in people with schizophrenia or severe mental health problems [14, 31, 39, 44]. SEM "is a statistical methodology that takes a confirmatory (i.e. hypothesis testing) approach to the analysis of a structural theory bearing on some phenomenon" [8].

However, so far and to the best of our knowledge, no studies using SEM explored the complex interrelations between self-stigma, individual social capital and empowerment among people with depressive disorders.

In this study we aimed to validate, in a large sample of people with MDD from across Europe, the hypothesis that poor individual social capital increases internalized stigma which, in turn, can hinder empowerment (black solid arrows, see Figure 1). In particular, we examined the hypothesis that poor individual social capital and higher self-stigma directly influences the level of empowerment. In addition, we tested simultaneously the hypothesis that social capital indirectly affects empowerment mediated through the intensity of reported self-stigma.

\section{Materials and methods}

\subsection{Study design}

This is a cross-sectional study conducted within the framework of the EU-funded-ASPEN study, a multi-site project aiming to address explore stigma and discrimination and related factors among acainst-people with depression across Europe [21]. An overall sample of 527 patients with a diagnosis of MDD were recruited across 19 sites located in 18 European countries (Belgium, Bulgaria, England, Finland, France, Germany, Greece, Hungary, Italy [Brescia and Verona], Lithuania, the Netherlands, Portugal, Romania, $\underline{\text { Scotland, Slovakia, Slovenia, Spain, and Turkey). Participants were interviewed face-to- }}$ face by trained researchers not involved in the care process with an extensive set of study instruments, including measures for empowerment and self-stigma (see paragraph 2.2). 
From the 19 ASPEN sites, 16 sites located in 15 countries also collected data on social capital ( $\mathrm{n}=433$ ) (Romania, Scotland and Spain did not participate in this assessment).

Full details on sample recruitment are given elsewhere [21]. In brief, between January and December 2010, a minimum of 25 participants in each participating site was consecutively recruited from local public or private specialist mental health services (outpatients and day care clinics) and assessed with the study instruments. This sampling method, also adopted in previous international multisite studies [41], was deliberately intended to allow local staff to take into account the specific local service configuration and to draw participants from the whole range of appropriate local services where people with MDD receive treatment from specialist mental health services. No compensation was provided for study participation. Inclusion criteria were: a diagnosis of Major Depressive Disorder (MDD) (single episode or recurrent) according to DSM-IV-TR criteria; a major depressive episode within the past 12 months (but not at time of interview); signed informed consent; ability to understand and speak the main local language; at least 18 years old. Exclusion criterion was: being a psychiatric in-patient at the time of recruitment. The study was approved by the local research Ethics Committee | at each study site.

\subsection{Measures}

\subsubsection{Social capital. For this study's aims, perceived social support, social network and} interpersonal trust were considered indicators at an individual level that we posited to be gathered under the umbrella term "søcial capital" [2]. We included three different indicators for evaluating individual social capital. Perceived social support was assessed with the Oslo 3-Item Social Support Scale [27], which eontained-contains three items concerning: number of people the participant reports being close to; concern shown by others; and ease of getting practical help from neighbours. It provides an overall social support index score where higher scores indicate tower-higher levels of social support. Using current data, Cronbach's alpha reliability was consistent with other studies and equal to $0.6[13,43]$. With regard to social network, three items from the European Social Survey (ESS) [15] (C2 C4)-were included, exploring relationships, reciprecity contacts in social life and level of participation in the community. The sum score of the se 
threeordinal-items gave the collective social network (ranging from 3 to 14, higher scores indicating higher social network) and a Cronbach's alpha of 0.64.-- Finally,өr for Interpersonal-interpersonal Frustrust, responses on three questions (A8 110)-from the ESS [15] on a 10-point Likert scale ranging from 0 ('no trust') to 10 ('highest trust') were collected; the score was calculated by combining the three items. Also for this measure, we found a Cronbach's alpha of 0.82 , which substantially overlaps with those reported in previous studies using the ESS [45, 33].

2.2.2 Self-stigma. The subjective experience of stigma was assessed with the Internalized Stigma of Mental Illness (ISMI) scale [35], which consists of 29 items each rated on a 4point Likert scale (ranging from 1= "strongly disagree" to $4=$ "strongly agree") with higher scores indicating higher internalized stigma. The ISMI includes five subscales: alienation, stereotype endorsement, discrimination experience, social withdrawal and stigma resistance. Since stigma resistance was found to be a separate construct [37], the stigma resistance subscale items in this study have not been included in the total ISMI score. Self-stigma is referred to the combined average of the other four ISMI subscales. Consistency measured by Cronbach's alpha was 0.89 .

2.2.3 Empowerment. Subjective feelings of empowerment (personal control, action, power sharing, dignity and equity)-were assessed using the Boston University Empowerment Scale (BUES) [36]. This scale-an instrument containsing 28 items

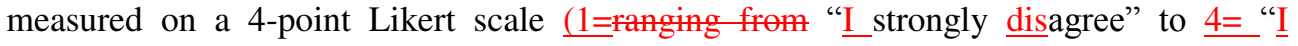
strongly disagree"). They are organized The BUES scale consists of inte five subscales: powerless/powerlessness, righteous anger, self-esteem/self-efficacy, community activism and autonomy, optimism and control over future. Higher score on each BUES subscales reflects high empowerment. Consistency (Cronbach's alpha) was 0.84.

\subsection{Statistical analysis}

Summary statistics were carried out through means and standard deviations (SDs) for continuous variables, and frequencies and percentages for discrete variables.

Preliminary aAssociations analysis -between individual socio-demographic (sexgender, age, family status, living situation, education, employment status) and clinical variables | 
(number of depressive episode, previous admission for psychiatric care, age at the first treatment for a mental health problem) with total ISMI and total BUES scores were examined by t-tests and two linear regression models (ISMI and BUES scores as dependent variables). Two analysis analyses of covariance (ANCOVA) adjusted for "country" factoreffect were applied to evaluate the putative significant relationship between self-stigma (as dependent variable) and empowerment, social support, interpersonal trust, social network (as independent variables), and between empowerment (as dependent variable) and social capital indicators (as independent variables).

We then examined tThe interrelations between observed and latent variables were studied by SEM [6]. The main advantage of using SEM is the flexibility to model complex relationships between one or more independent (exogenous) variables and one or more dependent (endogenous) variables simultaneously. Moreover, the contribution of each subscales to corresponding latent construct could be easily carried out. The goodness of fit of the model, to test if the hypothesized model is a plausible explanatory model for the empirical data, was checked by several measures: $\chi^{2}$ test, relative $\chi^{2}$ test and comparative fit index (CFI), root mean square error of approximation (RMSEA), Tucker-Lewis coefficient (TLI) and Akaike information criterion (AIC).

The hypothesized model (see Figure 1),-included three latent variables: self-stigma that was indexed with four subscale items of the Internalized Stigma of Mental IIlnessiSMI scale-(without the subscale stigma resistance); empowerment was measured using four subscales items of the BUES scale; social capital as the common factor of the three instruments was measured by the average scores of-social support, social networks and interpersonal trust subscales.

The model designated both social capital and self-stigma as predictors of empowerment, and self-stigma as mediator of empowerment.

Formatted: English (U.S.)

Formatted: English (U.S.)

Moreover, the observed variables: number of lifetime depressive episodes (categorized in two classes: $\leq 5$ vs. $\geq 6$ depressive episodes), previous psychiatric admissions (yes vs. no), employment status (paid work vs. unpaid work), were included in SEM model as exogenous variables based on their -significant associations with ISMI and/or BUES as detected in previous analyses.

Five hundred and sixteen patients who filled out both the ISMI and the BUES scales were included in the model. For those patients not assessed with social capital measures $8 / 21 \underline{22}$ 
(having been recruited in the three sites which did not consent to collect this additional information), missing data ( 83 for both social trust and support, 84 for social network) were handled by Bayesian multiple imputation [38]. This method ensures the stability of estimates that in our study were obtained by averaging across ten different imputed data sets [1]. Moreover, the Bayesian method allowed us to directly model the missing data process (through prior parameter specification) providing robust estimates also in case of violation of missing at random assumption. Missing data were handled by Bayesian multiple imputation [45]. Multivariate normal distribution assumption was tested and confirmed: skewness and Kurtesis-kurtosis or each parameter was between $\underline{t}$ 2. All statistical analysis were carried out by using SPSS 21.0, SEM was implemented by package AMOS 21.0. Statistical significance was set at $\mathrm{p}<0.05$.

\section{Results}

\subsection{Patients' characteristics}

Overall, 516 persons with MDD participated were selected in for the purpose of thise study. The socio-demographic and-clinical-characteristics of participants are given in Fable 1. From the overall sample recruited in the ASPEN study ( $\mathrm{n}=527), 516$ completed both the ISMI and BUES scales. Their socio-demographic and clinical characteristics are given in Table 1.

\section{$<$ Insert Table 1 about here>}

The mean age of respondents was $46.7-6$ years $(\mathrm{SD}=15.3)$, and-more than half were female $(68.2 \%)$, moreover; 4 47.7\% was married or co-habiting (47.7\%)-and $\underline{39.2 \%}$ hadeing a paid work-(39.2\%). The vast-majority of respondents $(96.8 \%)$ agreed with the diagnosis for which they were being treated. The mean age of first treatment for mental | illness was 35.8 years $\underline{(\mathrm{SD}=15.0)}$.

Table 2 provides the distributions of ISMI, BUES and social capital mean scores.

$<$ Insert Table 2 about here> 
For the 16 sites included in the study, $t$ The overall mean ISMI score was above the midpeint2.2 (range 1-4), thus indicating a low-moderate level of internalized stigma [7]. Similarly, the overall BUES mean score was above the midpoint2.7 (range 1-4), indicating moderate levels of endorsement of empowerment [7]. With regard to social support and social network, the mean scores were 8.9 and 8.3 in a range of 3-14, indicating that participants reported moderate-high levels of social support [27] and social network. Finally, the mean score of interpersonal trust (range 0-10) was equal to 4.6 $( \pm 2.1)$ that revealed a quite fair-moderate trust toward other people.

\subsection{Relationships between ISMI, BUES and Social Capital}

Associations between socio-demographic and clinical variables with ISMI and BUES respectively were tested to select variables to include in SEM (see Table 3a).

\section{$<$ Insert Table 3 and Table 4 about here>}

SexGender, age, family status, living situation, education, and age at first contact with mental health services were not significantly related to ISMI and BUES scores, hence none of them were included in the model. Previous psychiatric admissions were associated to higher ISMI scores $(\mathrm{p}=0.004)$. Unemployed people and participants with more than 6 lifetime depressive episodes were associated with higher ISMI scores | ( $\mathrm{p}<0.001 \_$and, $\mathrm{p}=0.004$ respectively) and lower BUES scores $\left(\mathrm{p}=0.020 \_\right.$and, $\mathrm{p}<0.001$ respectively).

Similarly, ANCOVA models, adjusted for site effectfactor, were used to select outcome variables to be included in the SEM model (see Table 3bㄴ). Significant inverse correlations were found between social capital indicators (social suppert, social network, interpersonal trust) and ISMI score. Higher scores on social support, social network, interpersonal trust were found associated to higher and-BUES scores-respectively. Moreover, Ltower BUES scores were significantly correlated to higher ISMI scores. Finally, comparison of ANCOVA models with and without adjustment for site effect factor were carried out: predictor estimates of two models did not differ, thus it was decided to not consider the "site" variable in SEM. 


\subsection{Structural equation model}

The hypothesized structural equation model (see Figure 1) involved all variables significantly associated to ISMI and BUES and the plausible relations between the latent constructs (circle in figure) and observed variables (rectangle in figure) are reported.

$<$ Insert Figure 1 about here $>$

There was no evidence of association effects of the between number of hospitalizations admission for psychiatric care and self-stigma. Moreover, - number of depressive episodes and employment were not found significantly associated neither on-with selfstigma or empowerment.- The final model is reported in Figure 2.

$<$ Insert Figure 2 about here>

The number of distinct parameters to be estimated was 45, including covariance parameters between exogenous variables for improving the model fit. Model fit indices showed a good fit for the data $\left(\chi^{2}=35.916, \mathrm{df}=32, \mathrm{p}=0.290_{2}\right.$; relative $\chi^{2}=1.122$, CFI $=$ $0.998 ;$;LI $=0.997$, RSMEA $=0.015$ (90\%CI 0.000-0.037) and AIC $=125.891)$.

Latent constructs were well defined by their indicators. By comparing the factor loading of social capital, we noted that the main contributors to the latent construct were given by social support and social network (with factor loading equal to 0.69 and 0.64 ); whereas the main contributors to the empowerment and self-stigma latent construct were given by self-esteem and optimism (with factor loading equal to 0.86 and 0.83 ) and social withdrawal and alienation (with factor loading equal to 0.87 and 0.84 ) respectively. Differently, righteous anger subscale had a low factor loading (0.08) and it was removed by from indicators of the latent variable empowerment. Social capital and self-stigma accounted for $56 \%$ of the total variability of participants' empowerment.Pirect, indirect and total effects of observed and latent constructs on self stigma and empowerment are shown in Table 4. 
1

Social capital had a direct and negative effect on self-stigma $(r=-0.72, p<0.001$ and $52 \%$ of self-stigma variability explained by social capital) indicating that higher social capital was related with lower self-stigma. Moreover, social capital had both a direct effect ( $\mathrm{r}=$ $0.27 \mathrm{p}<0.001)$ and an indirect effect_( $r=-0 \underline{0.38}, \mathrm{p}<0.001)$ on empowerment, suggesting that self-stigma partially mediated [4] the relationship between social capital and empowerment.

\subsection{Competitive hypotheses}

In order to refine the causal relationships between the variables specified in Figure 1, two further SEM models were tested for competitive hypotheses where levels of social capital are influenced by empowerment (gray dashed arrow A, Figure 1) or by self stigma (gray dashed arrow B, Figure 1) respectively. A modified-second model, equivalent to the first model except that social capital was treated as an outcome of empowerment, was tested. This second model also provided quite good fit to the data but slightly less than the first ene $\left(\chi^{2}=42.011, \mathrm{df}=32, \mathrm{p}=0.111 ; \mathrm{CFI}=0.996, \mathrm{RSME} \mathrm{A}=0.025\right)$. The direct paths frem empowerment to social capital and from self-stigma to empowerment were statistically significant (standardized direct effects equal to 0.37 and to 0.63 , respectively, $p<0.001$ ). The partially mediating effect of self stigma within the positive relationship between social capital and empowerment was also replicated in this model (standardized indirect effect equal to $0.43, \mathrm{p}<0.001)$.

For further comprehensive analysis, a third SEM model in which social capital was considered as mediator of the relations between self stigma and empowerment was investigated. In more detail, the difference between the first and third model is that selfstigma was considered as a source of influence on both social capital and empowerment (predicted dependent variables). This yielded a model with poor fit $\left(\chi^{2}=46.301, d f=32\right.$, $p=0.049, \mathrm{CFI}=0.994, \mathrm{RSMEA}=0.029)$.

\section{Discussion}

The aim of this study was to test inter-relationships between social capital, self-stigma and empowerment among people with MDD. SEM analysis confirmed that poor social capital contributes to increased self-stigma and indirectly hinder clients' empowerment. 
This result is in line with previous studies that pointed to a relationship between an aspect of social capital, namely social network, and self-stigma in people suffering from other psychiatric conditions [30, 39]. Similarly, a previous study [49] found that pPerceived devaluation and-discrimination, which implies awareness about mental illness' generat attitudes, was found to acts as a mediator between negative social interactions and another variable related to empowerment, such as poorer quality of life of people with mental health problems. [54] ameng severely ill patients.-Moreover, we confirmed that higher self-stigma contributed to a lack of empowerment [39, 44].

Our findings seem to indicate that self-stigma aets as a mediating variable that intervenes between social capital (including low perception of social support, low social networks and poor interpersonal trust) and empowerment among people with MDD. Results of our study support the hypothesis that social capital plays a key role in buffering $\underline{\text { is a predictor }}$ of the negative effects of self stigma empowerment among people with MDD, in particular, both directly and indirectly via the mediated effect of self-stigma. A possible

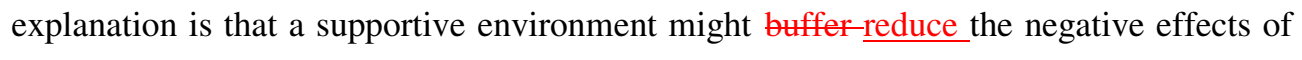
depression-related stigma and consequently build individual self-esteem and optimism.

The progressive model of self-stigma proposed by Corrigan [12] argued that stereotype awareness and stereotype agreement lead individuals to apply these views to one-self and to reduce self-efficacy and self-esteem. Self-stigma has been regarded as obverse of personal empowerment [37]. The fact that some individuals develop low self-esteem while others remain indifferent to stigma or react with empowerment and righteous indignation about discrimination - i.e., the "paradox of self-stigma and mental illness" [11] - seems to depend on in-group perception and the perceived legitimacy of the discrimination [37]. In fact, people with mental illness who hold their group in high regard or reject stigma as unfair are more likely to be more resilient to stigma by using positive strategy of coping [44].

The theory of the buffering effect [8] suggested-suggests that social support might operate as a moderator in to-reducinge the negative effects of stressors on psychological wellbeing. The original stress buffering model posited that at higher levels of stressful life events, the beneficial effect of social support on health is greater and viceversa [20]. Stigma and discrimination have beencan be conceptualized as a types of stressful events [5] and social support is thought as having a was found to act as a moderator buffering

Formatted: Not Highlight Formatted: Not Highlight Formatted: Not Highlight 
effect of adverse consequences of stressors by enhancing individuals' self efficacy [37].

Differently, our model shows that self-stigma is a mediator of the impact of individual social capital on empowerment. We assume that people experiencing more secial suppert and with higher interpersonal trust will suffer less from the negative consequences due to stigma. In the analyses of stress processes, stress related to prejudice and discrimination has been figured as an additional source of stress that acts as a mediator between a series of disadvantaged social statuses and mental health problems [28] and there is also evidence that stigma leads to depression [39]. In this regard, a previous study [17] proposed a model the model of positive and negative effects of social relationships on well being and depression by Ibarra Rovillard and colleagues [22] is of interest in which social relationships are considered to contribute to improved well-being when providing help to face negative life stressors (e.g. emotional support, instrumental support, informational support), but only when these acts are perceived as satisfying basic psychological needs (e.g. sense of belonging, feeling to be able to cope with difficulties).

We hypothesize that people with MDD's-perceptions of the availability of emotional support or advices on how to face problems may increase positive in-group perception of people with MDD [10]-and, in turn, decrease the likelihood of stereotype agreement. On the basis of our results, it is suggested that higher social capital might foster the level of individual sense of empowerment directly and also by reducing the appraisal of stigma as a source of stress. Social support from family, friends and social network and interpersonal trust may be considered social and psychological resources to cope with threats to individual identity as discrimination [5]. In this sense, family psycho-education, peer support and coaching should be stimulated in order to prompt the activation of supportive networks and to improve effective empowering coping strategies to enhance individual skills for coping with self-stigma [29]. However, there is also well established evidence in the literature suggesting that stigma negatively impacts on social networks of people with mental illness [27].

In line with these findings, we here tested a second model where-social capital was at dependent variable of empowerment rather than a predictor. Within this model, self stigma was found to be a partial mediator of the negative association between sociat eapital and empowerment. In addition, the direct significant path from empowerment toward social capital seems to suggest mutual relationship between these two variables. 
In particular, these results seems to be in line with the "Why try effect" theory [12], which argues that awareness of stigmatizing stereotypes might result in individuals' eroded empowerment and, in turn, in dispelling "behaviours related to goal attainment". Both models supported a mediating role of self stigma between social capital and empowerment. Self-stigma might be detrimental within the core networks by reducing supportive ties by the others or by using coping strategies such as secrecy and withdrawat that might lead to smaller social networks [40].

Moreover, sSome evidence suggests that therapeutic psychological interventions such as Cognitivecognitive-behavioural techniques, narrative enhancement or group-based acceptance and commitment therapy may have the potential to reduce self-stigma [29]. Moreover, anticipated and experienced discrimination from friends and family members were found to have a negative effect on access to social capital from these social networks $[54,58]$. In this sense, family psycho-education, peer support and coaching should be stimulated in order to prompt the activation of supportive networks and to improve effective empowering coping strategies to enhance individual skills for coping with self stigma [31].

SEM analyses did not provide any significant association between number of depressive episodes and previous psychiatric admissions with self-stigma. This is in line with previous studies which found that self-stigma does-did not predict clinical outcomes or medication adherence in depressed patients at 1-year follow up [50]. and it is not associated to duration of illness course among patients with schizophrenia [51]. In addition, although ANCOVA found an association between employment status and level of self-stigma, this relationship was not supported by SEM. Further research is required to explore whether depressed people with lower income would have reduced access to social capital compared to people with a higher income. It is possible that a lower access to social resources such as social support, might decrease resilience to stigma and discrimination. Consistent with previous studies [14, 31], we found that self-stigma was not significantly associated with any other socio-demographic variables.

This study has a number of limitations. Its cross-sectional design prevented us from | establishing relations of longitudinal-causality and this study did not address other possible factors that could explain more variance in the empowerment construct. Unfortunately, we did not have data on psychopathology or personality structures in our 
sample because these assessments were beyond the scope of the study. Hence, data need to be interpreted with caution, since reports of low social capital may reflect a consequence of depression's severity and negative cognitive style [42] rather than representing an independent variable. In line with previous research, we found that most participants reported low levels of self-stigma $[7,14]$ and moderate-high levels of social support and social network [39]. Potential selection bias (i.e. $84 \%$ of the sample were eutpatients) should be taken into account.-For example, $84 \%$ of the sample were postacute outpatients, for this reason -people who never accessed professional care were under-represented. There are _numerous factors that may influence the self-stigma process, so further studies should include target populations such as groups who are marginalised due to aspects of social circumstances (i.ee.g.-, economic disadvantage) or through aspects of identity (i.e.e.g., ethnicity).

\section{Conclusions}

Despite these limitations, wWe found empirical evidence that self-stigma partially mediates the positive could moderate the impact ofrelationship between social capital $\underline{\text { anden individual sense of empowerment. Therefore, ifn order to improve-increase }}$ empowerment of people with MDDdepression, this study pointed out the need for identifying strategies to foster at the individual level and the improvement of cognitive individual social capital (comprising of the perceptions of support, reciprocity in social life, sharing and trust among people-) should be pursuedwith MDD.

Disclosure of interest: The authors declare they have no conflicts of interest.

\section{Acknowledgments}

\section{The ASPEN Study Group @ 2012}

Staff at Co-ordinating Centres: Graham Thornicroft, Tine Van Bortel, Samantha Treacy, Elaine Brohan, Shuntaro Ando, Diana Rose (King's College London, Institute of Psychiatry, London, England); Kristian Wahlbeck, Esa Aromaa, Johanna Nordmyr, Fredrica_Nyqvist, Carolina Herberts (National Institute for Health and Welfare, Vaasa, Finland); Oliver Lewis, Jasna Russo, Dorottya Karsay, Rea Maglajlic (Mental Disability Advocacy Centre, Budapest, Hungary); Antonio Lasalvia, Silvia Zoppei, Doriana I 
Cristofalo, Chiara Bonetto (Department of Public Health and Community Medicine, Section of Psychiatry and Clinical Psychology, University of Verona, Italy); Isabella Goldie, Lee Knifton, Neil Quinn (Mental Health Foundation, Glasgow, Scotland); Norman Sartorius (Association for the improvement of mental health programmes (AMH), Geneva, Switzerland).

Staff at Partner Centres: Chantal Van Audenhove, Gert Scheerder, Else Tambuyzer (Katholieke_Universiteit Leuven (K.U. Leuven), Belgium; Valentina Hristakeva, Dimitar Germanov (Global Initiative on Psychiatry Sofia (GIP-Sofia), Bulgaria); Jean Luc Roelandt, Simon Vasseur_Bacle, Nicolas Daumerie, Aude Caria (Etablissement Public Santé Mentale Lille-Métropole (EPSM/C.C.OMS), France); Harald Zaske, Wolfgang Gaebel (Heinrich-Heine Universitat Dusseldorf, Rheinische Kliniken Dusseldorf (RKD), Germany); Marina Economou, Eleni Louki, Lily Peppou, Klio Geroulanou (University Mental Health Institute (UMHRI (EPIPSI), Greece); Judit Harangozo, Julia Sebes, Gabor Csukly (Awakenings Foundation (AWF), Hungary); Giuseppe Rossi, Mariangela Lanfredi, Laura Pedrini (Unit of Psychiatry, IRCCS Istituto Centro San Giovanni di Dio Fatebenefratelli,-di Brescia, Italy); Arunas Germanavicius, Natalja Markovskaja, Vytis Valantinas (Vilnius University (VU), Lithuania); Jaap van Weeghel, Jenny Boumans, Eleonoor Willemsen, Annette Plooy (Stichting Kenniscentrum Phrenos (KcP), Netherlands); Teresa Duarte, Fatima Jorge Monteiro (Associaçãopara o Estudo e Integração Psicossocial (AEIPS), Portugal); Janka Hurova, Dita Leczova (Association for Mental Health INTEGRA, o. z. (Integra o.z.), Slovakia); Vesna Svab, Nina Konecnik (University Psychiatric Hospital (PKL), Slovenia); Alp Ucok, Gulsah Karaday (Foundation of Psychiatry Clinic of Medical Faculty of Istanbul (PAP), Turkey).

Funding: European Union in the framework of the Public Health Programme. 


\section{References}

[1] Allison PD, Missing data techniques for structural equation modeling. J Abnorm Psychol 2003;112:545-57.

[2] Barney LJ, Griffiths KM, Jorm AF, Christensen H. Stigma about depression and its impact on help-seeking intentions. Aust N Z J Psychiatry 2006;40:51-4.

[3] Baron S, Field J, Schuller T (eds). Social capital. Critical Perspectives. London: Oxford University Press; 2000.

[4] Baron RM, Kenny DA. The moderator mediator variable distinction in social psychological research: Conceptual, strategic, and statistical considerations. J Pers Soc Psychol 1996;51:1173-182.

[5] Berjot S, Gillet N. Stress and coping with discrimination and stigmatization. Front Psychol 2011;2-33.

[6] Bollen KA. Structural equation with Latent Variables. New York: John Wiley ed.; 1996.

[7] Brohan E, Gauci D, Sartorius N, Thornicroft G, GAMIAN-Europe Study Group. Selfstigma, empowerment and perceived discrimination among people with bipolar disorder or depression in 13 European countries: the GAMIAN-Europe study. J Affect Disord 2011;129:56-63.

[8] Cohen S, Wills TA. Stress, social support, and the buffering hypothesis. Psychol Bull 1985;98:310-57.

[9] Coleman J (1988). Social capital in the creation of human capital. Amer J Sociol 94,S95-S120.

[10] Corrigan PW. Impact of consumer-operated services on empowerment and recovery of people with psychiatric disabilities. Psychiatr Serv 2006;57:1493-96.

[11] Corrigan P, Watson AC The Paradox of Self-Stigma and Mental Illness Clin Psychol Sci Pr 2002;9:35-53.

[12] Corrigan P, Watson AC. The impact of stigma on severe mental illness. Cog Behav Pract 1998;5:201-222.

| [13] -Dalgard OS, Dowrick C, Lehtinen V, Vazquez-Barquero JL, Casey P, Wilkinson G, et al. Negative life events, social support and gender difference in depression: a multinational community survey with data from the ODIN study. Soc Psychiatry Psychiatr Epidemiol. 2006;41:444-51. 
[14] Drapalski AL, Lucksted A, Perrin PB, Aakre JM, Brown CH, DeForge BR, et al. A model of internalized stigma and its effects on people with mental illness. Psychiatr_Serv 2013;64:264-69.

[15] European Social Survey. ESS Round 5 Source Showcards. London: Centre forComparative Social Surveys. London: City University; 2010.

[16] Gaudiano BA, Miller IW. Self-stigma and attitudes about treatment in depressed patients in a hospital setting. Int J Soc Psychiat 2013;59:586-91.

[17] Ibarra-Rovillard MS, Kuiper NA. Social support and social negativity findings in depression: perceived responsiveness to basic psychological needs. Clin Psychol Rev 2011;31:342-52.

[18] Kawachi I, Subramanian SV, Kim D. Social Capital and Health. New York: Springer-Verlag; 2007.

[19] Kelly BD, Davoren M, Mhaolain AN, Breen EG, Casey P. Social capital and suicide in 11 European countries: an ecological analysis. Soc Psychiatry Psychiatr Epidemiol 2009;44:971-977.

[20] Kim SS, Chung Y, Perry MJ, Kawachi I, Subramanian SV. Association between interpersonal trust, reciprocity, and depression in South Korea: a prospective analysis. PLoS One. 2012;7:e30602.

[21] Lasalvia A, Zoppei S, Van Bortel T, Bonetto C, Cristofalo D, Wahlbeck K, et al. Global pattern of experienced and anticipated discrimination reported by people with major depressive disorder: a cross-sectional survey. Lancet 2013;381:55-62.

[22] Lin N. Social Capital. A Theory of Social Structure and Action. Cambridge: Cambridge University Press; 2001.

[23] Link BG, Cullen FT, Struening E, Shrout PE, Dohrenwend BP. A Modified Labeling Theory Approach to Mental Disorders: An Empirical Assessment. Am Sociol Rev 1989;54:100-23.

[24] Livingston JD, Boyd JE. Correlates and consequences of internalized stigma for people living with mental illness: a systematic review and meta-analysis. Soc Sci Med 2010;71:2150-161.

[25] Lundberg B, Hansson L, Wentz E, Björkman T. Are stigma experiences among persons with mental illness, related to perceptions of self-esteem, empowerment and sense of coherence? J Psychiatr Ment Health Nurs. 2009;16:516-22.

[26] McNair BG, Highet NJ, Hickie IB, Davenport TA. Exploring the perspectives of people whose lives have been affected by depression. Med J Aust. 2002;176 Suppl:S6976.

Field Code Changed

Field Code Changed

Field Code Changed

Field Code Changed

Field Code Changed

Field Code Changed

Field Code Changed

Field Code Changed

Field Code Changed

Field Code Changed 
[27] Meltzer H. Development of a common instrument for mental health. In: Nosikov \& Gudex (eds), Eurohis: Developing Common Instruments for Health Survey. Amsterdam: IOS press; 2003. p. 35-47.

[28] Meyer IH, Schwartz S, Frost DM. Social patterning of stress and coping: does disadvantaged social statuses confer more stress and fewer coping resources? Soc Sci Med. 2008; 67:368-79.

[29] Mittal D, Sullivan G, Chekuri L, Allee E, Corrigan PW. Empirical Studies of SelfStigma Reduction Strategies: A Critical Review of the Literature. Psychiatr Serv 2012;63:974-81.

[30] Mueller B, Nordt C, Lauber C, Rueesch P, Meyer PC, Roessler W. Social support modifies perceived stigmatization in the first years of mental illness: a longitudinal approach. SocSci Med 2006;62:39-49.

[31] Munoz M, Sanz M, Perez-Santos E, Quiroga Mde L. Proposal of a socio-cognitivebehavioral structural equation model of internalized stigma in people with severe and persistent mental illness. Psychiatry Res 2011;186:402-08.

[32] Murray CJL, Lopez AD. The Global Burden of Disease: a comprehensive assessment of mortality and disability from diseases, injuries, and risk factors in 1990 and projected to 2020. Cambridge: Harvard University Press; 1996.

[33] Poortinga W. Social capital: an individual or collective resource for health? Soc Sci Med 2006; 62:292-02.

[34] Putnam R. Bowling Alone. The Collapse and Revival of American Community. New York: Simon \& Schuster; 2000.

[35] Ritsher JB, Otilingam PG, Grajales M. Internalized stigma of mental illness: psychometric properties of a new measure. Psychiatry Res 2003;121:31-49.

[36] Rogers ES, Chamberlin J, Ellison ML, Crean T. A consumer-constructed scale to measure empowerment among users of mental health services. Psychiatr Serv 1997;48:1042-47.

[37] Rusch N, Lieb K, Bohus M, Corrigan PW. Self-stigma, empowerment, and perceived legitimacy of discrimination among women with mental illness. Psychiatr Serv 2006;57:399-02.

[38] Schafer JL. Analysis of incomplete multivariate data. Chapman \& Hall ed. London; 1997.

[39] Sibitz I, Amering M, Unger A, Seyringer ME, Bachmann A, Schrank B, et al. The impact of the social network, stigma and empowerment on the quality of life in patients with schizophrenia. Eur Psychiatry 2011;26:28-33. 
[40] Song L. Social capital and psychological distress. J Health Soc Behav 2011;52:47892.

[41] Thornicroft G, Brohan E, Rose D, Sartorius N, Leese M; INDIGO Study Group. Global pattern of experienced and anticipated discrimination against people with schizophrenia: a cross-sectional survey. Lancet 2009; 373:408-15.

[42] Tse WS, Bond AJ. The impact of depression on social skills. J Nerv Ment Dis 2004; 192:260-8.

[43] Van Lente E, Barry MM, Molcho M, Morgan K, Watson D, Harrington J, et al. Measuring population mental health and social well-being. Int J Public Health. 2012; 57:421-30.

[44] Vauth R, Kleim B, Wirtz M, Corrigan PW. Self-efficacy and empowerment as outcomes of self-stigmatizing and coping in schizophrenia. Psychiatry Res 2007;150:7180.

[45] Von dem Knesebeck O, Dragano N, Siegrist J. Social capital and self-rated health in 21 European countries. Psychosoc Med 2005; 23;2:Doc02.

[46] Webber M. Huxley P, Harris T. Social capital and the course of depression: six| month prospective cohort study. J Affect Disord 2011;129:149-57.

[47] Webber M, Corker E, Hamilton S, Weeks C, Pinfold V, Rose D, et al. Discrimination against people with severe mental illness and their access to social capital: findings from the Viewpoint survey. Epidemiol Psychiatr Sci 2013;20:1-11.

[48] World Health Organization. World health report 2001: New understanding, new hope. Geneva: WHO; 2001.

[49] Yanos PT, Rosenfield S, Horwitz AV. Negative and supportive social interactions and quality of life among persons diagnosed with severe mental illness. Community Ment Health J 2001;37:405-19.

[50] Yen CF, Chen CC, Lee Y, Tang TC, Ko CH, Yen JY. Association between quality of life and self-stigma, insight, and adverse effects of medication in patients with depressive disorders. Depress Anxiety 2009;26:1033-9.

[51] Zoppei $S_{\&}$ Lasalvia $A_{\&}$ Bonetto $C_{\Omega}$ Van Bortel $T_{2}$ Nyqvist $F_{2}$ et al. Social capital and reported discrimination among people with depression in 15 European countries. Soc Psychiatry Psychiatr Epidemiol 2014 [Epub ahead of print]
Field Code Changed

Field Code Changed

Formatted: English (U.S.)

\begin{tabular}{|l|}
\hline Formatted: English (U.S.) \\
\hline Formatted: English (U.S.) \\
\hline Field Code Changed \\
\hline Formatted: English (U.S.) \\
\hline Field Code Changed \\
\hline Formatted: English (U.S.) \\
\hline Formatted: English (U.S.) \\
\hline Formatted: English (U.S.) \\
\hline Field Code Changed \\
\hline Formatted: English (U.S.) \\
\hline Formatted: English (U.S.) \\
\hline Field Code Changed \\
\hline Formatted: English (U.S.) \\
\hline Formatted: English (U.S.) \\
\hline Field Code Changed \\
\hline Formatted: English (U.S.) \\
\hline Field Code Changed \\
\hline
\end{tabular}


Figure 1. Hypothesized effects of social capital and self-stigma on empowerment, controlled for admission for psychiatric care, number of depressive episodes and employment status.

Figure2. Structural equation model: the rectangles represent the observed variables; the gray elliptic circles symbolize the latent variables. Significance of standardized regression weights is represented with asterisks: ${ }^{*} \mathrm{p}<0.05$; ${ }^{* *} \mathrm{p}<0.001$. White elliptic circles represent variables error. 